\title{
El "Escudo de Heracles" de Hesíodo: écfrasis y narración en la épica arcaica
}

DAVID KONSTAN

Brown University

RESUMO: No "Escudo de Heracles" e no carmen 64 de Catulo (o "epitalâmio" de Peleu e Tétis), a écfrasis ocupa praticamente a metade do poema. Embora a de Catulo descreva como Teseu abandona Ariadne e consista, dessa forma, numa narrativa paralela à historia principal, o escudo hesiódico não é uma narrativa propriamente dita e, sim, uma seqüência de imagens distintas que existem simultaneamente, como em um desenho. Este artigo examina como a écfrasis hesiódica detém o movimento do tempo narrativo e apresenta uma comparação detalhada do "Escudo de Heracles" com a descrição do escudo de Aquiles na llíada. Embora ambas as écfrasis suspendam o tempo narrativo, a de Hesíodo é mais fiel à simultaneidade das artes plásticas.

PALAVRAS-CHAVE: Écfrasis; narrativa; Hesíodo; Homero; Catulo.

También yo creo, Nicocles, que las imágenes de los hombres son un buen medio para recordarlos, $y$, sin embargo, las de sus acciones y su pensamiento son mucho más importantes (Isócrates, Evágoras 73).

Es un tópico afirmar que las representaciones gráficas se diferencian de los relatos verbales en el uso que hacen del tiempo. Los relatos deben referir los acontecimientos en una sucesión temporal: primero oyes una cosa, luego otra, y es imposible contar toda la secuencia simultáneamente. Y esto es cierto incluso cuando el orden en que se cuenta una historia es distinto del supuesto orden cronológico de los acontecimientos narrados. Por ejemplo, una novela puede comenzar con el relato de una ejecución y remontarse después hasta el principio de los hechos para explicar, en progresión lógica, cómo se cometió el delito y cómo fue capturado el delincuente. Pero incluso así el narrador respeta el principio de sucesión y no puede presentar todas las fases de la acción en un solo aliento o una sola página'

Las artes plásticas, por el contrario, pueden mostrar una secuencia completa de acontecimientos como coexistentes en un momento dado ${ }^{2}$. Sobre un tapiz, o en un friso, el artista puede representar el comienzo y final de un viaje marítimo y también la nave en un punto medio de su travesía, y quien observe el conjunto podrá percibir todas estas imágenes simultáneamente. El espectador tiene la libertad de empezar por el punto que él elija, o retroceder y contemplar de forma panorámica la totalidad del lienzo. La obra en sí, incluso si contiene imágenes que, leídas narrativamente, no han podido ocurrir al mismo tiempo, revela cada momento, por así decirlo, 
sub specie aeternitatis, bien entendido que por "eternidad" queremos indicar aquí no una duración infinita de tiempo sino más bien algo próximo a lo que San Agustín denominaba la simultaneidad de todos los momentos en la mente de Dios.

Sin embargo, cuando se describe una obra pictórica en una narración oral o literaria, ésta debe presentarse, inevitablemente, episodio por episodio. Así, una écfrasis se diferencia necesariamente de una representación visual o plástica porque la écfrasis impone sobre la obra que copia sus propias restricciones temporales ${ }^{3}$. Si un poeta, por ejemplo, está describiendo un viaje, le resulta imposible mostrar todas sus fases en un único diseño, y se verá forzado a contarlas con un cierto orden, cualquiera que éste sea. El poeta puede elegir comenzar por el final e ir retrocediendo hasta el comienzo, en cuyo caso el orden del relato será opuesto al de los sucesos descritos; pero, en cualquier caso, la simultaneidad se perderá.

Para ejemplificar este punto, podemos considerar brevemente dos écfrasis de la Eneida de Virgilio. La primera es la secuencia de imágenes en el templo de Juno del libro I, que decribe escenas de la guerra de Troya. Eneas, al contemplar estas imágenes, espera un tratamiento humano por parte de los habitantes de la región a donde ha llegado tras su naufragio, y reflexiona sobre el hecho de que aquí también sunt lacrimae rerum et mentem mortalia tangunt. Pero, dado que las imágenes están esculpidas en un templo dedicado a Juno, muy bien pudiera ser que hubieran sido diseñadas para celebrar el triunfo griego más que para suscitar compasión por los vencidos troyanos; es, por tanto, verosímil, que Eneas interpretara erróneamente el mensaje que pretendían transmitir ${ }^{4}$. Sea esto como sea, lo que me interesa mostrar aquí es que Eneas contempla las diversas ilustraciones sucesivamente; por decirlo con las palabras mismas que usa Virgilio, videt Iliacas ex ordine pugnas (1.456). Primero, la muerte de Reso, luego la de Troilo (este episodio rompe el orden de acontecimientos de la Ilíada), y luego la muerte de Héctor a manos de Aquiles y cómo éste arrastra el cadáver tres veces en torno a la ciudad de Troya, seguido por la imagen de Príamo suplicando que se le devuelva el cuerpo de su hijo. A este episodio le sigue, a su vez, la llegada de Memnón y Pentesilea, todo en el orden debidos.

La segunda écfrasis que me gustaría mencionar es la que adorna las puertas del oráculo Sibilino en Cumas, y que había sido esculpida por el maestro Dédalo ${ }^{6}$. Una vez más, el orden de imágenes es estrictamente cronológico: el asesinato de Androgeo, el hijo de Minos, y, a continuación, la multa que los atenienses debían pagar cada siete años - la palabra tum (6.20) se refiere tanto a la secuencia de imágenes como a la sucesión temporal de los acontecimientos. También se representa el amor de Pasífae por el toro y el Minotauro que resultó de esa unión, junto con el laberinto y la pasión de Ariadna por Teseo. También Ícaro, dice Virgilio, habría tenido un lugar en la obra si el dolor de Dédalo lo hubiera permitido (sineret dolor, 6.31); pero las manos del padre fracasaron dos veces al intentar representar la muerte de su hijo. Con ello indica Virgilio la tensión existente dentro del artista entre su impulso por completar su relato y su relación personal con el tema, que le impide describir acontecimientos demasiado cercanos. Eneas y sus compañeros, nos dice Virgilio, habrían examinado con atención todos los episodios (quin protinus omnia perlegerent oculis, 6.33-34), si Acates y la sacerdotisa no hubieran interrumpido su inmersión en el espectáculo (spectacula) y le hubieran ordenado preocuparse de los necesarios sacrificios 7 . Así pues, también el deseo del espectador de alcanzar la conclusión de la historia queda truncado, 
igual que había sucedido con el deseo de Dédalo de esculpirla. Tanto para el artista como para el receptor, la narrativa se organiza como un vector que apunta hacia adelante en el tiempo.

Estos ejemplos ilustran cómo la literatura ha proyectado sobre la pintura su propio compromiso con una secuencia temporal de acontecimientos. Las artes plásticas, cuando se decriben en poesía, tienden a asumir el impulso narrativo específico del medio literario. A su vez, las artes visuales parecen haber incorporado, en el período romano e, incluso, en edades anteriores como la época clásica en Grecia el imperativo narrativo de la literatura. Resulta difícil no ya reproducir en palabras una obra de arte visual sino incluso sencillamente contemplarla, sin imponer sobre ella la organización narrativa que, al principio de este trabajo, hemos considerado como, en principio, ausente de las artes plásticas, que más bien tienden a detener al flujo del tiempo ${ }^{8}$. A pesar de la distinción que Lessing trazó en su Laocoonte entre artes visuales y verbales, da la impresión de que la narrativa tiende a conquistarlo todo ${ }^{9}$.

El ejemplo más importante de écfrasis que encontramos en literatura romana antes de Virgilio es la que nos ofrece el poema 64 de Catulo, llamado a veces el "Epitalamio de Tetis y Peleo", y es esta obra la que nos remite al mundo de la poesía arcaica que es el tema principal de mi trabajo. En un artículo publicado en 1993 aventuré la sugerencia de que Catulo podría haber modelado su epilio directamente sobre el "Escudo de Heracles" de Hesíodo. La discusión de las fuentes de este poema se divide normalmente en dos posiciones: (1) Catulo tomó como base de su epilio un poema helenístico, ahora perdido, que habría seguido muy fielmente, como Wilamowitz, por ejemplo, supuso, o (2) compuso su poema sin ningún modelo griego específico, aunque tenía deudas obvias con la poesía helenística en cuanto a su técnica de composición. Es este último punto de vista el que ha ganado preeeminencia entre los críticos contemporáneos y hoy se estudia por lo general el poema 64 de Catulo como una composición latina original. Esta posición es plausible, pero, sin embargo, podemos también defender que Catulo estructuró su epilio sobre el "Escudo" hesiódico en particular, a pesar de las manifiestas diferencias entre ambos poemas.

La principal semejanza entre ambos poemas, y la más relevante para nuestro tema, es la longitud de sus respectivas écfrasis, que, en cada caso, ocupan aproximadamente la mitad de la composición - un poco más de la mitad en Catulo 64, un poco menos en el "Escudo". Pero esto no es todo. Aunque el "Escudo" circuló como obra independiente en el período helenístico, y Catulo lo habría conocido en esa forma, originariamente iba unido al también hesiódico "Catálogo de las mujeres" o "Eeas," y siguió mostrando trazas de esa unión. Así, aunque el tema principal del "Escudo" sea el encuentro entre Heracles y Cicno, el hijo de Ares, el poema se abre con la historia de Alcmena, la madre de Heracles, y los primeros cincuenta y seis versos nos cuentan cómo Zeus aprovechó la ausencia de Anfitrión para dormir con ella; Alcmena dio a luz a Heracles, hijo de Zeus junto con su mellizo Ificles, hijo mortal de Anfitrión. Luego el poeta salta abruptamente al viaje de Heracles, ya adulto, a Tracia, durante el cual Cicno intentará bloquearle el camino. Este cambio repentino de espacio y tiempo también se produce, paralelamente, en el poema 64 de Catulo, que comienza cuando se bota a la Argo y luego, tras treinta líneas, salta hasta la boda de Peleo y Tetis, quienes, en la versión que Catulo da del mito, se conocieron cuando la Argo inició su expedición. Catulo 
ofrece luego una pequeña descripción del palacio de Peleo antes de entrar propiamente en la écfrasis, que relata las imágenes bordadas en el cobertor del lecho nupcial de Tetis. En el poema de Hesíodo, también una descripción de las armas de Heracles sirve como transición a la écfrasis, que describe las imágenes grabadas en el escudo del héroe.

Pero, si ambos poemas comienzan de forma similar, hay también correspondencias en las partes que siguen tras las respectivas écfrasis, aunque no me detendré en su detalle. Pues lo que me interesa hoy no es documentar la influencia del "Escudo" de Hesíodo sobre el poema 64 de Catulo, sino señalar las diferencias existentes entre la écfrasis de Catulo y la del "Escudo", incluso si es cierto, como yo propongo, que Catulo tuvo presente este poema arcaico cuando compuso su propio epilio.

El tapiz nupcial que describe Catulo contiene cinco escenas distintas que, tomadas juntas, cuentan el viaje de Teseo a Creta para salvar a sus conciudadanos atenienses del sacrificio que anualmente tenían que hacer al Minotauro, tanto como su subsiguiente retorno a Atenas. En orden cronológico, los episodios descritos incluyen la huida de Teseo con Ariadna, el abandono de ésta en la isla de Naxos, la llegada de Teseo a su patria, en la cual olvida cambiar sus velas negras por las blancas y con ello provoca, sin querer, la muerte de su padre, y, finalmente, la llegada de Dioniso y sus Ménades a Naxos, que puede presagiar el matrimonio del dios con Ariadna. Catulo no representa los diversos episodios en este orden, sin embargo. Más bien, entremezcla tres escenas en Naxos - el abandono de Ariadna, su lamento, que forma el cuadro central, y el momento en que Dioniso y su grupo se acercan - con una visión retrospectiva de las aventuras de Teseo en Creta y, tras el lamento de Ariadna, una anticipación de la muerte de Egeo, que Catulo trata como un castigo merecido por haber abandonado a Ariadna (en ambas ocasiones Teseo olvida algo) y como consecuencia directa de la maldición de la princesa. Sin embargo, a pesar de la dislocación temporal de la narrativa, las escenas del cobertor representan colectivamente una sola historia, que se centra en el abandono de Ariadna e incluye tanto el incidente de Creta que desembocaría en ese abandono como lo que les sucedió después tanto a ella como a Teseo.

Por qué Catulo eligió contar la historia de Teseo y Ariadna en el contexto de un poema nupcial en honor de Tetis y Peleo, es materia de controversia; yo tengo mi propia opinión, pero no necesitamos detenernos en ello ahora. Es claro que existe un cierto contrapunto entre la feliz ocasión del matrimonio y la historia trágica de muerte y deserción pintada en el cobertor. También existe una analogía, quizás, entre la unión de Peleo con una diosa y el matrimonio de Ariadna, si eso es lo que la escena de hecho insinúa, con el dios Dioniso. Pero, sea cual fuere el motivo por el que Catulo contó esta historia, su écfrasis registra una secuencia coherente de acontecimientos, en una forma que hemos visto también como característica del estilo ecfrástico de Virgilio. Es verdad que Catulo rompe el orden de presentación e incluye dos episodios que están desplazados temporalmente, el uno dedicado a los acontecimientos que preceden al abandono, en tanto que el otro cuenta los que siguieron a partir de ahí. En este sentido, las escenas del cobertor se adaptan a la naturaleza de las artes visuales o plásticas, que representan como simultáneo lo que en una narrativa verbal transcurre en el tiempo. En una tapicería auténtica, podemos mirar de un lado al otro, sin considerar el orden cronológico de las escenas. Los episodios bordados en la écfrasis de Catulo, sin embargo, cuentan una historia coherente, y Catulo ofrece varias marcas tempo- 
rales para dejar muy claro el orden de los sucesos. Además, la historia representada en el cobertor se organiza de forma más lineal que el marco narrativo que cuenta las aventuras de Peleo y su matrimonio con Tetis.

¿Dónde se inspiró Catulo para presentar su écfrasis como una narrativa por derecho propio? El poema de Mosco sobre el rapto de Europa, compuesto en el siglo segundo a.C. contiene una breve écfrasis que ilustra el destino de Ío, que había sido también víctima del interés amoroso de Zeus. De manera que la écfrasis relata una historia paralela a la del marco narrativo, y es posible que este poema diera a Catulo la idea de organizar el tema del bordado del cobertor como una unidad narrativa que sirviera de contrapunto a la historia que la enmarcaba. Pero, naturalmente, Catulo no lleva su imitación de Mosco hasta el límite, y en su poema la conexión entre marco y digresión no es tan obvia como la que existe entre el episodio de Europa y el de Ío, donde, como afirma Alessandro Perutelli (Perutelli, 1978, p. 92) "un mito puede ser leído a través del otro".

Pero volviendo al "Escudo de Heracles" hesiódico, podemos comenzar por notar que el marco narrativo presenta una organización simple, lineal: tras la escena de apertura, que trata de Alcmena y el nacimiento de Heracles, el poema se centra en un solo acontecimiento -- la rivalidad entre Heracles y Cicno, y sus consecuencias. Heracles se arma, entabla combate con Cicno, lo mata y hiere a su padre, Ares, tras lo cual prosigue su viaje hacia Tracia. La acción, por tanto, avanza de forma más directa que en la narración principal de Catulo, que se detiene, por ejemplo, para presentar a las Parcas cantando las futuras hazañas de Aquiles en Troya, y termina con una queja sobre la depravación de los tiempos modernos en contraste con la edad de los héroes cuando los dioses se manifestaban en persona a los seres humanos.

En contraste con esto, la écfrasis de Hesíodo, que se dedica a una descripción del escudo de Heracles, carece por completo del impulso narrativo que caracteriza el relato de Catulo del tapiz nupcial. El escudo está saturado de imágenes. En medio está el Terror, que mira con ojos brillantes y una fiera sonrisa; en torno a su ceño revolotea Eris, sembrando el terror entre los humanos. Persecución y Contra-Persecución están también grabadas en el escudo, seguidas por el Estruendo, la Matanza y el Asesinato. Todas estas figuras no guardan ningún orden particular, y aunque que todas representan aspectos de la batalla no hay una historia que justifique esta distribución. Son, más bien, meras representaciones icónicas. Hefesto había grabado también una docena de cabezas de serpientes, que resuenan cuando Heracles entra en combate; el poeta nota el extraordinario azul oscuro de sus lomos y sus negras fauces. También se representa allí un enfrentamiento entre leones y jabalíes que se disputan la carroña de dos cabras. Sigue a continuación la guerra de Lapitas y Centauros, y una escena con el propio Ares, acompañado por el Terror y el Miedo. En otra parte del escudo hay una semblanza de Atenea, y, cerca de ella, Apolo tocando la lira en medio de un coro de dioses. Una escena de un puerto muestra unos delfines que chapotean en el agua, y otra representa a Perseo con la cabeza de la Gorgona; por encima de esta imagen, el fragor de una batalla en torno a una ciudad fortificada, y, junto a ello, una ciudad en paz, donde se está celebrando una fiesta además de juegos, una cacería, y otras actividades.

Sea cual sea el principio que pone en relación estas imágenes dispares, no se basa en un orden narrativo. Peter Toohey (Toohey, 1988, p. 20-25; cf. Janko 1986, p. 40) ha argumentado que el papel de Perseo, cuyas hazañas aparecen más o menos en la mitad de la 
écfrasis, debe entenderse como contrapuesto a la carrera de Heracles ${ }^{10}$. Sea esto como sea, la historia de Perseo es tan sólo un pequeño segmento del grandioso diseño del escudo y, en cualquier caso, es bastante diferente del tratamiento que Catulo da a la historia de Teseo y Ariadna. Pues el relato de Perseo constituye no tanto una narrativa diferenciada cuanto un elemento puntual más en el complejo patrón visual.

En el escudo de Hesíodo, hay una ausencia virtualmente completa de marcadores temporales en las descripciones de escenas - las sucesivas imágenes no van puntuadas por partículas tales como "luego," "a continuación," o "después". Ninguna de ellas aparece, por ejemplo, en el relato de Perseo, y, más aún, las únicas que yo he detectado en toda la écfrasis se encuentran en el breve episodio de los leones y los jabalíes, donde leemos las partículas $n u$, êdê, y eti $(170,172,176)$, aunque éstas, a mi juicio, tienden más a confirmar la simultaneidad de los diversos momentos que a señalar su disposición temporal. En el "Escudo de Aquiles" homérico, nor el contrario, hay numerosos adverbios temporales, tales como entha, epeita, ou pô, hote, autika, hopote, opisthe, allote (18.497, 506, 513, 520, 531, 544, 554, 602; cf. 522, 523, 545, etc.), así como indicadores del movimiento (takha, aipsa, $525,532)$ que ayudan a organizar las escenas individuales cronológicamente. En tanto que la sucesión de imágenes, en su conjunto, no muestra una progresión lineal, si las consideramos individualmente son más compatibles con el movimiento narrativo del resto de la épica que los símbolos que adornan el escudo de Heracles ${ }^{11}$.

La écfrasis de Hesíodo interrumpe el avance de la narración que la enmarca. En lugar de formar un contrapunto con el marco narrativo, muestra, más bien, la disposición decorativa u ornamental, atemporal, que es característica de las artes visuales ${ }^{12}$. En vez de partículas temporales, el poema de Hesíodo ofrece adverbios espaciales, tales como en, epi, heterôthen, huper, peri, y proparoithe $(144,147,184,237,279,285)$, o meros indicadores de repetición y paralelismo, como aute (296). Desde luego, las diversas imágenes se decriben sucesivamente, pues ésta es la única forma en que la poesía puede representarlas. Tanto Homero como Hesíodo, además, respetan la convención de describir el escudo en el momento en que es fabricado, según Hefesto va inscribiendo ahora una, luego otra de las imágenes ${ }^{13}$. A pesar de ello, sin embargo, en ninguno de los dos poemas hay una indicación fuerte de orden temporal en la actividad artesana del dios: en vez de expresiones tales como "en primer lugar hizo," "y luego esculpió," encontramos una mera repetición de frases tales como "había allí...," etc. El contraste con el ornato del templo de Cumas realizado por Dédalo y que describe Virgilio, donde tanto el artista como el que lo contempla se ven impelidos por un deseo narrativo, no podría ser más acusado.

Así pues, en la écfrasis arcaica, y más concretamente en el escudo de Heracles, el espacio reemplaza al tiempo como principio regulador. ¿Por qué es esto así y cuál es su importancia para nuestra comprensión de la poesía arcaica? Sentimos la tentación de buscar una respuesta en lo que sabemos sobre las artes plásticas en la época de la poesía hesiódica. Aunque éste no es el momento de investigar este asunto en detalle, merece la pena mencionar el Vaso François, que es el vaso más famoso de esta época, y que sigue desafiando los intentos de los críticos por descubrir un patrón o relato coherente en la multiplicidad de imágenes que adornan su superficie. Así pues, las artes plásticas parecen no haberse sometido aún, en tiempo de Homero y Hesíodo, al imperativo narrativo que, en gran medida, dará un 
principio de organización a obras de arte posteriores ${ }^{14}$. En vez de subordinar el arte a la narrativa, la descripción verbal se adapta al carácter no-lineal del objeto visual.

Otro rasgo de la écfrasis arcaica que puede ser relevante para su disposición atemporal es el énfasis que se pone en la materialidad del objeto de arte descrito. Mientras que la poesía posterior, como en Catulo y Virgilio, sólo alude levemente a la materia prima -piedra, metal, o tejido - que subyace a la obra de arte visual, en la écfrasis de Homero y especialmente en la de Hesíodo ésta parece mantener su identidad incluso después de recibir las imágenes figurativas $^{15}$. Así, en el escudo de Heracles leemos que había unos delfines de plata, bajo los cuales (hupo, 213) unos peces de bronce iban huyendo. Así también, los Lapitas han sido esculpidos en plata, pero la armadura que llevan es de oro (183; cf. 199, 243, 271, 313). Hay también expresiones que insisten en la vivacidad de las imágenes y que sirven para recordar al lector su corporeidad: así, se nos dice que, en la ciudad asediada, las mujeres que están en la torre son como seres vivos (244; cf. 198). Pero el grupo más concentrado de referencias al material aparece en la descripción de Perseo, a quien las manos de Hefesto han modelado en oro (219-20), aunque su espada era de hierro oscuro (melandeton, 221); su zurrón es de plata, pero con flecos de oro (224-26). Hesíodo nos dice que Perseo se parecía a un hombre apresurado y estremecido (228). Lo más notable de todo es la manera en que la figura de Perseo apenas toca la superficie del escudo con sus pies, y parece más bien flotar sobre él (217-18). Es como si la imagen estuviera a punto de liberarse de la materia que la contiene. Pero la misma imposibilidad de tal relieve atrae la atención, de nuevo, sobre la naturaleza material del medio. Incluso cuando describe la viveza de las formas esculpidas en el escudo, la écfrasis de Hesíodo insiste en la materia de que se componen. El poeta arcaico es extremadamente consciente de la calidad física del objeto que está describiendo en palabras.

La técnica metalúrgica que Hesíodo describe parece remontar a época micénica, y, según parece, era desconocida en el período arcaico. Puede ser, como Beth Cohen me ha sugerido, que al poner el énfasis en la producción del objeto se acentuara su condición prehistórica, y ello representaría, por tanto, simbólicamente, la pretérita edad heroica. O puede ser que, en la época de Hesíodo la poesía tenía una especial tendencia a reflexionar sobre el proceso de composición, ya fuera verbal o artístico, y se deleitara al hacerlo manifiesto, tal como las novelas modernas como Don Quijote, Tristram Shandy, o Jacques le fataliste de Diderot, muestran a las claras su condición de artefactos narrativos, y parecen anticipar con ello las metanarrativas de la literatura posmoderna.

Es, finalmente, posible, que las écfrasis de Homero y Hesíodo reflejaran una tradición literaria que se desarrolló, en su día, en paralelo al modelo narrativo que da vida a las grandes épicas. (Debo esta idea a conversaciones con Pura Nieto). Este modo poético alternativo podría haber dejado huella también, por ejemplo, en los símiles homéricos, que normalmente adoptan la forma de viñetas intemporales (nótese que los tiempos verbales preferidos son el aoristo intemporal o el presente), aunque a veces dejan entrever una tendencia narrativa propia, tomada, quizás, del ambiente -dominado por la trama- que las rode ${ }^{16}$. No deberíamos pasar por alto la posibilidad de que el escudo de Hesíodo sea un testimonio importante de una tradición de este estilo, que encontramos latente pero que un día gozó de vitalidad y que resurge periódicamente en poesía posterior como, por ejemplo, en los adornos que decoran la copa descrita en el primer Idilio de Teócrito. 
En el "Escudo de Heracles" tal como lo tenemos la écfrasis está, naturalmente, enmarcada en un episodio narrativo, en el que se presenta, aparentemente, como una digresión. Pero se diferencia de las digresiones ordinarias y de las écfrasis tardías que se parecen a digresiones porque no introduce una narrativa secundaria como contrapunto al movimiento primario del relato, sino que tiene, más bien, el efecto de suspender el movimiento progresivo del recital, y sustituye el ímpetu temporal de la narrativa por una construcción verbal de un tipo diferente. Esta fidelidad de la écfrasis al medio plástico no debería ser contemplada como una parataxis primitiva, sino más bien como un logro artístico que es, muy posiblemente, resultado de una tradición secular de composición oral. El hecho de que en el escudo hesiódico los pasajes narrativos y la écfrasis atemporal tengan peso casi igual es, creo yo, signo de una estética bastante diferente del modo narrativo más uniforme que gobierna la literatura clásica en general, al menos hasta los últimos siglos del Imperio Romano (vease Roberts, 1989). La crítica moderna tiene aún que desarrollar un acercamiento adecuado a este extraordinario equilibrio entre descripción temporal y atemporal en uno de los poemas más antiguos y menos apreciados de la antigüedad griega. La tarea nos espera.

\section{Notas}

1 - Putnam (1998, p. 2) remite a Krieger (1992, p. 1-28) para el punto de vista de que "the ideal, but unrealizable, goal of ekphrasis is to stop time, to place narrative momentum in a subservient position to the object under scrutiny".

2 - Esta es al menos la manera en que las pinturas se representan a sí mismas; Sharrock (1996, p. 106) nota que los cuadros, también "read over time," aunque fingen ofrecer una visión simultánea de los hechos. Así también, Laird (1996, p. 96) nota que, "like a verbal narrative or a poetic utterance, a picture is taken in serially".

3 - Fowler (1991, p. 27) habla de una "narrative impurity" que penetra en la descripción, y observa: "clearly narration often continues through a description (there is rarely a complete pause)". Laird (1996, p. 97) señala que, en la teoría antigua, "a description of a visual representation of an event would be narratable in the same way as the event itself".

4 - Así Horsfall, 1990; cf. Fowler, 1991, p. 32-33 para un punto de vista matizado. Sobre esta écfrasis en general, vease Laird, 1996, p. 87-91; Putnam, 1998, p. 23-54; para la relación de Juno con los acontecimientos descritos, p. 24. Por los murales sabemos que Dido conoce ya los principales sucesos de la guerra de Troya; el hecho de que le pida a Eneas que se los cuente sugiere que lo que desea saber no son nuevos hechos, sino más bien el punto de vista de los vencidos troyanos; cf. Putnam, p. 41.

5 - Compárese la écfrasis histórica, modelada sobre Virgilio, en Silio Itálico 6.653-97, con la discusión de Fowler, 1996, p. 63-64; Fowler también comenta sobre escenas descritas por Filóstrato en la Vida de Apolonio de Tiana 2.20, que, una vez más, sigue una secuencia cronológica.

6 - Sobre este episodio en general, vease Putnam, 1998, p. 75-96.

7 - Como Elsner (1996, p. 1) indica, Servio ad loc. ya había conectado la frase perlegerent oculis con la lectura.

8 - La tendencia a leer el arte histórico romano como narrativa está implícita, por ejemplo, en la asociación entre monumentos históricos y textos literarios, tal como las res gestae imperiales de Augusto y Trajano; cf. Elsner, 1996b, Huet, 1996; Huet señala que las interpretaciones modernas, sin embargo, tienden a ver narrativas lineales donde las obras originales invitaban a lecturas más complejas. 
9-Sobre el punto de vista de Lessing de la descripción homérica del escudo de Aquiles como impulsada por la narrativa, v. Becker, 1995, p. 13-22. Podemos notar que la écfrasis de Virgilio del escudo de Eneas sigue el orden de la secuencia histórica de los acontecimientos grabados en él y que describen los momentos más importantes en la evolución del estado romano. Para una discusión de este escudo, v. Laird, 1996, p. 77-81; Putnam, 1998, 119-88. Putnam, p. 154, contrasta la "time-committed narrative" de las imágenes con la circularidad física del escudo mismo; también llama la atención (p. 155, 161-62) sobre el recurso de la repetición, que establece una cierta tensión con la linearidad de la narrativa.

10 - En la cerámica clásica, el equilibrio de las imágenes predomina sobre la narrativa como principio organizador; cf. Lissarague, 1994, p. 18-19. Pero Lissarague nota que, en tanto que las imágenes pueden estar asociadas, no hay principios consistentes que indiquen cómo se relacionan unas con otras; de ahí que, "There is no way for the modern interpreter to verify those associations" (p. 24).

11 - Becker (1995, p. 152) comenta sobre el escudo de Aquiles: "The Shield appropriates visual images by translating them into stories. The translation includes motion, thought, motive, cause and effect, prior and subsequent action, and sound". Para el efecto del movimiento en las imágenes del escudo de Eneas virgiliano, v. Putnam, 1998, p. 19.

12 - Putnam (1998, p. 10) señala con elegancia acerca de una écfrasis engarzada que "two types of narrativity collide" (cf. p. 12, 36); en el caso de Hesíodo, sin embargo, la acción dentro de la écfrasis es tan reducida como para poner en cuestión la aplicabilidad del término "narrative". Putnam en otro lugar (p. 21) se refiere a la écfrasis como un lugar donde "the narrative momentarily rests".

13 - En contraste, el escudo de Eneas, en la épica de Virgilio, se describe en el momento en que el héroe lo recibe, más que durante el proceso de su fabricación; vease Lessing, 1984, p. 84; también Putnam, 1998, p. 13; para las diferencias entre las écfrasis griega arcaica y virgiliana, cf. p. $120,167$.

14-Spivey (1996, p. 31) nota que las esculturas arcaicas "were mainly either monoscenic or synoptic," y pone como ejemplo el pedimento del templo de Ártemis en Corfú (principios del siglo VI a.C.) como "a sculptural programme within a restricted space which sacrifices continuity of narrative to a synoptic vision of events". El pedimento tiene como figura central la cabeza de la Gorgona. Sobre el carácter sinóptico del arte griego antiguo, v. Snodgrass, 1982; Connelly, 1993, p. 107. Connelly nota (p. 119) que la transición en la cerámica de figuras negras a figuras rojas fue también acompañada de un cambio, al menos parcial, en la dirección de un mayor interés narrativo de una forma que ella describe como "episódica".

15 - Sobre las referencias al medio físico en los escudos homérico y hesiódico, v. Becker, 1995, p. 32-33, 152-53. En la descripción del escudo de Eneas en el libro VIII de la Eneida, Virgilio imita a Homero y Hesíodo al referirse ocasionalmente a los metales en que están grabadas las imágenes; v. Putnam, 1998, p. 3.

16 - Sobre la semejanza entre símiles y écfrasis en Virgilio, v. Becker, 1995, p. 49-50, Putnam, 1998, p. 11.

\section{Referencias bibliográficas}

BECKER, Andrew Sprague. The shield of Achilles and the poetics of ekphrasis. Lanham: Rowman and Littlefield, 1995.

CONNELLY, Jane Breton. "Narrative and image in Attic vase painting: Ajax and Kassandra at the Trojan Palladion". En HOLLIDAY, 1993, p. 88-129. 
ELSNER, Jas, ed. Art and text in Roman culture. Cambridge: Cambridge University Press, 1996.

(1996a). “Introduction”. En ELSNER, 1996.

. (1996b). "Inventing imperium: texts and the propaganda of monuments in Antiquity". En ELSNER, 1996, p. 32-53.

FOWLER, D.P. "Narrate and describe: the problem of ekphrasis". JRS, v.81, p. 25-35, 1991.

FOWLER, Don. "Even better than the real thing: a tale of two cities". En ELSNER, 1996, p. 57-74.

GOLDHILL, Simon; OSBORNE, Robin, edd. Art and text in ancient GreekcCulture. Cambridge: Cambridge University Press, 1994.

HOLLIDAY, Peter J., ed. Narrative and eaent in ancient art. Cambridge: Cambridge University Press, 1993.

HORSFALL, Nicholas. "Dido in the light of History". En HARRISON, S. J., ed. Oxford readings in Vergil's Aeneid. Oxford: Clarendon Press, 1990 [orig. 1973-74]. p. 127-40.

HUET, Valérie. "Stories one might tell of Roman art: reading Trajan's Column and the Tiberius cup”. En ELSNER, 1996, p. 9-31.

KONSTAN, David. "Neoteric epic: Catullus 64". In BOYLE, A.J., ed. Critical essays on Roman literature: epic. London: Routledge, 1993. p. 59-78.

KRIEGER, Murray. Ekphrasis: the illusion of the natural sign. Baltimore: The Johns Hopkins University Press, 1992.

LAIRD, Andrew. "Ut figura poesis: Writing art and the art of writing in Augustan poetry". En ELSNER, 1996, p. 75-102.

LESSING, Gottfried E. Laocoön: on the limits of painting and poetry. Trad. E.A. McCormick. Baltimore: The Johns Hopkins University Press, 1984.

LISSARAGUE, François. "Epiktetos egraphsen: the writing on the cup”. En GOLDHILL \& OSBORNE, 1994, p. 12-27.

PERUTELLI, Alessandro. "L'inversione speculare: per una retorica dell'ekphrasis". $M D$, v. 1, p. 87-98, 1978.

PUTNAM, Michael C.J. Virgil's epic designs: ekphrasis in the Aeneid. New Haven: Yale University Press, 1998.

ROBERTS, Michael. The jeweled style: poetry and poetics in late Antiquity. Ithaca: Cornell University Press, 1989.

SHARROCK, Alison. "Representing metamorphosis". En ELSNER, 1996, p. 103-30.

SNODGRASS, Anthony M. Narrative and allusion in archaic Greek art. London: Leopard's Head, 1982.

SPIVEY, Nigel. Understanding Greek sculpture: ancient meanings, modern readings. London: Thames and Hudson, 1996. 
KONSTAN, David. The Hesiodic "Shield of Heracles": ecphrasis and narration in archaic epic. Classica, São Paulo, 13/14, p. 59-69, 2000/2001

ABSTRACT: In both the Hesiodic "Shield of Heracles" and c. 64 by Catullus (the epithalamium for Peleus and Thetis), an ecphrasis occupies approximately half the entire poem. But while Catullus' ecphrasis describes the abandonment of Ariadne by Theseus, and thus constitutes a parallel narrative to the main story, the Hesiodic shield is not a straightforward narrative but a sequence of distinct images that exist simultaneously, as in a picture. This paper examines the function of the Hesiodic ecphrasis in stopping narrative time. In particular, a detailed comparison of the "Shield of Heracles" with the description of Achilles' shield in the lliad indicates that although both ecphrases halt narrative time, the Hesiodic is more faithful to the simultaneity of pictorial art.

KEYWORDS: Ecphrasis; narrative; Hesiod; Homer; Catullus. 